\title{
EDITORIAL
}

\section{A new tool for an old disease}

\author{
B. Khanavkar, S. Ewig
}

Over the last two decades, interventional techniques in bronchology, including airway stenting, have become an accepted and widely used method for the relief of critical airway stenoses [1]. Currently, main indications are bridgeable malignant stenoses in the course of palliative care. Another field of experience with stents has unfolded in lung transplant surgery with regard to anastomosis problems. In addition, stent placement to consolidate mechanical or laser re-opening of a stenosed bronchus is a feature of "high-tech" medicine [2].

Incidence of tuberculosis in "high-tech" areas has been falling as a result of improved living conditions, as well as effective and timely treatment. Accordingly, bronchial tuberculosis as a late complication in pulmonary tuberculous disease has become a rarity in industrialised countries [3]. However, it still remains a considerable clinical problem in high-incidence regions, such as large parts of Africa and Asia [4].

The natural history of bronchial involvement in tuberculosis almost invariably leads to a degree of luminal stricture [5] and, in addition, often remains quite refractory to drug treatment [6]. Conversely, early relief of tuberculous bronchial stenosis clearly has the potential to prevent the destruction of pulmonary lobes by atelectasis and bronchiectasis, the socalled post-tuberculous syndrome. In an attempt to prevent the development of bronchial strictures, some authors have recommended that anti-tuberculous treatment be augmented by corticosteroids, but results of recent studies have been inconclusive [7, 8].

The standard of care in this context is the surgical approach [9]. It entails open thoracic surgery and the technique of sleeve resection in order to save areas for ventilation. Success has been documented for this approach and in most cases surgery offers a permanent solution to the problem. Although multiple stenoses increase the invasiveness of the procedure, surgery is still considered to be the method of choice [10] in the absence of a convincing effect of anti-inflammatory drugs such as corticosteroids.

Considering this standard of care, the report on endobronchial relief for tuberculous bronchial stenoses, by using interventional bronchoscopic techniques, by Low et al. [11] in this issue of the European Respiratory Journal is promising. In fact, "high-tech" experience applied to bronchial complications of a widespread disease has the potential for the development of new therapeutic options.

Interventional bronchoscopic techniques and the placement of silicone stents require the help of rigid bronchoscopy, yet rigid bronchoscopy compared with chest surgery is an easy feat and placing one or several stents technically does not

Klinik für Pneumologie, Infektiologie und Beatmungsmedizin, Augusta-Kranken-Anstalt, Bochum, Germany.

Correspondence: B. Khanavkar, Klinik für Pneumologie, Infektiologie und Beatmungsmedizin, Augusta-Kranken-Anstalt, Bochum, Bergstrasse 26, Bochum D-44791, Germany. Fax: 49 2345172463. E-mail: khanavkar@augusta-bochum.de complicate the procedure. The results reported by Low et al. [11] are considerable. Luminal diameters pre- and postprocedure were documented to increase on average by a factor of 2.6 in tracheal and 3.2 in bronchial lesions, comparing well with instant relief of dyspnoea reported previously for this method for other indications $[12,13]$. Two severely ill patients were even taken off mechanical ventilation immediately after the intervention and no complications of the procedures were reported. Many strictures occurred in the left main bronchus, which seems to be a position with favourable pre-dilection for this method.

A moderate length follow-up ( 25 months) in the study by Low et al. [11] provides some useful information on the drawbacks encountered by this type of management. A total of 10 out of 21 patients continued to have symptoms ranging from cough to repeated chest infections and one patient proceeded to pneumonectomy for infectious problems. In addition, no information is communicated about a correlation between the chronicity of bronchial stenosis (12 patients were classified as "inactive tuberculosis") and continuing symptoms. These results suggest that re-opening pulmonary regions that have been damaged by long-standing central stenoses might not be helpful for the relief of symptoms, whereas the early prevention of bronchial obstruction in the course of active antituberculous treatment makes very good sense. A well-tolerated procedure of low invasiveness may help prevent later surgery.

A clear message from the paper by Low et al. [11] is the need for repetition of interventional procedures (one third of the group). Stent migration, restenosis and granulation tissue can complicate the ensuing course; well documented complications in the context of endobronchial management of stenoses [13]. Additional potential problems also have to be taken into account. Airway dilatation on its own generally is of limited use, since cicatrical narrowing tends to recur [14]. Conversely, stent placement, as reported in this issue, cannot easily be achieved in all bronchial positions without covering other bronchial segments in close proximity, causing artificial narrowing.

Overall, many long-term problems may challenge the impressive results achieved with an intervention. Does this procedure offer a permanent solution to the problem? Do we subject patients to repeated endoscopical procedures this way? Tuberculosis is a disease encountered in younger years; can silicone stents be safely left in place? What are the later complications of such a foreign body in the airways? There are few reports on problems encountered in individuals carrying silicone stents permanently $[15,16]$. In our experience, accidental dislocation emergency intubation, airway perforation and infection problems with a colonised biofilm inside the stents can endanger long-term users.

Beyond these potential problems and complications, there remain many questions unanswered. Silicone stents have the advantage of being removable without complications even after many years in place. However, can airway stents safely be explanted again under such conditions and after what time 
span? Will cicatrical post-tuberculous stenoses recur after stent removal? Conditions favouring endoscopic management, such as early disease with viable lung behind strictures, location in the left main bronchus or the type of airway involvement (granuloma, compression or ulcerative lesion [6]), need further exploration.

In any case, we strongly suggest a meticulous follow-up of these patients to be able to better define the differential indications for surgery and endobronchial interventional techniques.

An afterthought may be allowed: the data presented by Low et al. [11] may stimulate interest for all those concerned with female issues; bronchial tuberculosis predominates in females, an observation repeatedly made by other investigators [9]. A satisfying explanation for this phenomenon has not yet emerged and should further motivate all investigators in this field to clarify the reasons for this observation.

\section{References}

1. Bolliger CT, Mathur PN, Beamis JF, et al. ERS/ATS statement on interventional pulmonology. Eur Respir $J$ 2002; 19: 356-373.

2. Bolliger CT. Airway stents. Sem Respir Crit Care Med 1997; 18: $563-570$

3. Hillejan L, Nemat A, Marra A, Stamatis G. Indication, type of resection and results of surgery in cases of lung tuberculosis. A historical and regional overview. Pneumologie 2002; 56: 345-348.

4. Kashyap S, Mohapatra PR, Saini V. Endobronchial tuberculosis. Indian J Chest Dis Allied Sci 2003; 45: 247-256.

5. Smith LS, Schillaci RF, Salin RF. Endobronchial tuberculosis: serial fiberoptic bronchoscopy and natural history. Chest 1987; 91: 644.

6. Nemir RL, Cardona J, Lacouius A, David M. Prednisone therapy as an adjunct in the treatment of lymph nodebronchial tuberculosis in childhood: a double blind study. Am Rev Tuberc 1963; 74: 189.

7. Oka M, Fukuda M, Nakano R, et al. A prospective study of bronchoscopy for endotracheobronchial tuberculosis. Intern Med 1996; 35: 698-703.

8. Takahashi N, Horie T. Medical treatment for bronchial stenosis due to endobronchial tuberculosis. Kekkaku 1999; 74: 885-889.

9. Watanabe $\mathrm{Y}$, Murakami S, Oda M, et al. Treatment of bronchial stricture due to endobronchial tuberculosis. World J Surg 1997; 21: 480-487.

10. Grillo HC. Notes on the windpipe. Ann thorac Surg 1989; 47: 9-26.

11. Low S-Y, Hsu A, Eng P. Interventional bronchoscopy for tuberculous tracheobronchial stenosis. Eur Respir J 2004; 24 : 345-347.

12. Stephens KE Jr, Wood DE. Bronchoscopic management of central airway obstruction. J Thorac Cardiovasc Surg 2000; 119: 289-296.

13. Bolliger CT, Probst R, Tschopp K, Soler M, Perruchoud AP. Silicone stents in the management of inoperable tracheobronchial stenoses. Chest 1993; 104: 1653-1659.

14. Chhajed PN, Malouf MA, Glanville AR. Bronchoscopic dilatation in the management of benign (non-transplant) tracheobronchial stenosis. Intern Med $J$ 2001; 31: 512-516.

15. Dumon JF, Cavaliere S, Diaz-Jimenez JP, et al. Seven-year experience with the Dumon prosthesis. J Bronchology 1996; 3: 6-10.

16. Colt HG, Dumon JF. Airway stents. Present and future. Clin Chest Med 1995; 16: 465-478. 